\title{
THE EFFECT OF PENICILLIN ON RHEUMATOID ARTHRITIS *
}

BY

EDWARD W. BOLAND, NATHAN E. HEADLEY, and PHILIP S. HENCH

\author{
Medical Corps of the Army of the United States
}

The cause of rheumatoid (atrophic) arthritis is unknown. Of the many aetiological theories the microbic hypothesis is still the most widely accepted, and of the many different bacteria which have been incriminated, haemolytic streptococci have been, since 1929, most under suspicion. Haemolytic streptococci from time to time have been recovered from the synovial fluid and blood, from foci of infection, and occasionally from synovial membrane, blood, and lymph nodes of patients with rheumatoid arthritis. The blood of the majority of patients who have this disease contains antibodies against haemolytic streptococci-that is, agglutinins, generally in high titre, and precipitins for the $\mathrm{C}$ substance of haemolytic streptococci. Although the concentration of antistreptolysins and antifibrolysins in the blood is not increased, except in some early or acute cases, the skin of patients with rheumatoid arthritis often is found to be hypersensitive to extracts of haemolytic streptococci. Such is the direct and indirect evidence on which the argument against haemolytic streptococci has been based. But since many patients with unmistakable rheumatoid arthritis do not present such evidence, the hypothesis has bcen presumptive only.

Ever since it was announced that penicillin was extremely effective against a variety of infectious agents, including haemolytic streptococci, many physicians and a host of rheumatic patients have been hopefully awaiting news that penicillin might prove effective against rheumatoid arthritis, although the sulfonamides, also effective against haemolytic streptococci, have proved useless against this disease. Hence this investigation.

\section{Plan of Investigation}

Two chief policies governed our investigation.

1. Policy Regarding Selection of Cases.-The only cases chosen for trial of treatment with penicillin were those in which the disease had advanced far enough to be diagnostically unmistakable but not far enough to have produced irreversible changes (destruction of cartilage and subchondral bone, notable flexion deformities), the presence of which might have made difficult a clear-cut evaluation of results.

2. Policy Regarding Dosage.-We decided to give penicillin long enough and in large enough doses so that, were our results negative, it could not well be said that our patients had not received sufficient amounts of the material. Ten patients have been treated intensively; all were male soldiers recently on active duty; their ages were from 23 to 45 . The average duration of the disease was $7 \cdot 4$ months.

\footnotetext{
* Abridged from a paper in the Jcurnal of the American Medical Association (1944, 126, 820-823), by courtesy of the Editor.
}

The sedimentation rates varied from 21 to 55 (Wintrobe).

\section{Summary of the Results}

1. Penicillin was given to ten soliders with early but progressive rheumatoid arthritis.

2. Large doses of penicillin were given intramuscularly every three hours day and night. The daily doses of penicillin were from 120,000 to 320,000 Oxford units; total doses were from $1,800,000$ to $3,250,000$ units within fourteen to twenty days. Such large doses are known to be adequate-indeed, perhaps more than adequate-against even severe infections (with or without bacteriaemia) from haemolytic streptococci, staphylococcus aureus, and so forth.

3. Our clinical results from penicillin, given in the doses stated over a period of fourteen to twenty-one days, were essentially negative. In 7 of the 10 cases there was no significant subjective or objective improvement. One patient felt worse but did not appear to be in worse condition than before treatment. In one case there was slight subjective, but no objective, improvement. One patient experienced moderate objective and subjective improvement in some, but not in all, of his joints; the sedimentation rate increased slightly during treatment, and he was by no means cured or even decidedly improved. In view of the capricious nature of rheumatoid arthritis the improvement in these two cases must be regarded as unrelated to the penicillin.

4. There was no definite evidence of improvement as measured by laboratory tests. There was no significant improvement in sedimentation rates or in the comparative leucocyte counts on synovial fluid made before and after treatment.

5. Definite improvement in appetite was noted by 6 of the 10 patients. It may have been unrelated to treatment with penicillin or it may have been a general side effect thereof.

\section{Conclusions}

1. Our results offer no support to the idea that haemolytic streptococci may be aetiologically related to rheumatoid arthritis.

2. In view of these negative results with rather large doses of penicillin, it seems reasonable to assume that rheumatoid arthritis is not caused by any of the bacteria which are already known to be rapidly affected by penicillin.

3. From these negative results we would conclude that penicillin probably should not be used for the further clinical treatment of rheumatoid arthritis, at least until the material is available in something approaching inexhaustible quantities. 